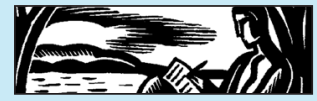

\title{
'The game becomes the mediator of all your relationships': Life Narrative and Networked Intimacy in Nina Freeman's Cibele
}

\author{
Rob Gallagher
}

King's College London

\section{ABSTRACT}

Nina Freeman's 2015 videogame Cibele recounts its creator's experience of falling in love with a fellow player of an online game. An interactive autobiography about a young woman sharing her life online, Cibele explores the terms on which new media enable users to narrate their experiences, represent themselves and forge identities. This article locates the game in relation to recent developments in life writing and independent game design, asking what digital technologies offer autobiographers as medium and as subject matter. It also frames Cibele as an attempt to challenge two dominant discourses about online culture: offering a counterpoint to narratives stressing the dangers facing young women who seek intimacy on the internet, Cibele also questions framings of networked intimacy as a necessarily deficient substitute for "the real thing." Its oblique approach, however, in tandem with its commitment to witnessing the ambivalences and incoherencies of digital culture, have, I argue, led to these points being missed or misinterpreted by players, reflecting a longstanding tendency to dismiss and devalue women's life writing.

Keywords: videogames, postfeminism, intimacy, online culture, gender, autobiography

\section{INTRODUCTION}

Set in 2009 and released in 2015, Nina Freeman's Cibele portrays a young North American woman grappling with the complications of networked 
self-presentation, friendship and romance. It sees both Nina, as protagonist, and Freeman, as autobiographer ${ }^{1}$, sharing their lives in ways that require them to reckon with misogynistic stereotypes of women guilty of 'oversharing' or revealing 'too much information'. ${ }^{2}$ Players watch Nina as she learns to navigate online spaces in which users can't be sure who will witness their acts of self-presentation and how those acts will be received. They also watch her cultivating a kind of mediated intimacy that, as I will argue, begs to be read as something other than an ersatz substitute for the fullness of embodied co-presence. But while Cibele has a lot to say-about gender, about digital mediation, about desire- the game has also been criticised for not saying enough, supposedly failing to assign the events it portrays a clear moral or meaning. Here I read Cibele as an attempt to say both too much and too little: mobilizing a range of media to share a personal coming of age story, Freeman also punctuates the account she gives with gaps, silences and equivocations, creating a space where the assumptions that players bring to the text (and to their online lives) can be recognised and re-evaluated.

\section{CIBELE IN CONTEXT}

Belonging to an ongoing series of autobiographical games portraying episodes from Freeman's childhood (2014's how do you Do It? and Ladylike), adolescence (2017's Lost Memories Dot Net) and young adulthood (2015's Freshman Year), Cibele stands at the intersection of several recent cultural trends. From the perspective of gaming culture, Freeman's work is part of an explosion of independent and amateur game creation catalysed by new development tools and distribution platforms. Enabling designers working alone or in small teams to quickly create and publish short games, these tools have helped to make autobiographical videogames "an emergent "genre" within independent game production over the past ten years.' As Cindy Poremba argues, digital games lend themselves to exploring the idea of 'the self as an active agent' and to highlighting the 'play between the self and its representation'. ${ }^{4}$ Such themes have been central to the work of designers like Anna Anthropy and Mattie Brice, whose pioneering autobiographical games helped to set a precedent for Freeman's work by riffing on the rulesets and aesthetics of classic videogames in order to highlight the quotidian challenges and no-win situations faced by women, queers and people of colour navigating white, heteropatriachal culture. ${ }^{5}$

Cibele and Lost Memories Dot Net also belong to a wave of so-called "desktop simulators" that mimic the interfaces of digital systems and devices to 
raise questions about intimacy, consent, and the vicissitudes of growing up online, assuming a form similar to Christine Love's Digital: A Love Story or Accidental Queens' A Normal Lost Phone. Insofar as it incorporates personal photos and private chatlogs into a kind of fictionalised autobiography, meanwhile, Cibele marks Freeman out as belonging to a 'generation of millennial women writers who share the details of their personal lives in a form of autofiction heavily influenced by blogging and social media' ${ }^{6}$ Describing authors like Sheila Heti, Lena Dunham and Emily Gould in terms of their shared investment in 'a poetics of oversharing', ${ }^{\text {vi }}$ Rachel Sykes argues that while these women are often "categorized as racy, daring, and guilty of sharing "too much" by their critics', such responses to their calculatedly 'mundane' portrayals of middle-class 'lives... [that] only marginally differ from presumed racial and sexual norms' are themselves excessive, suggesting just how repressive constraints on women's self-expression remain, 'even, or perhaps especially, when their work depicts the personal, sexual, and intellectual lives of white, heterosexual North American' subjects ${ }^{7}$ - a reading that illuminates Cibele's reception.

To fully understand this reception we must also address the gender politics of gaming culture. Gaming communities have long proven inhospitable to women, thanks in part to a male-dominated industry's reluctance to look beyond its traditional target demographic of young men responsive to heteromasculine power fantasies. ${ }^{8}$ By the mid 2000s, however, the aforementioned proliferation of more accessible gaming platforms, development tools and distribution methods was beginning to fuel visions of a more inclusive, diverse, politically engaged and aesthetically experimental videogame culture. In 2014 these visions elicited a highprofile backlash in the form of \#gamergate. A social media movement ostensibly concerned with journalistic ethics, gamergate provided an alibi for attacks on critics and designers (a disproportionate number of them female) whose work was seen by reactionaries as threatening the survival of both "real" videogames and an authentic "gamer" identity. Reviews and discussions of Cibele on platforms like Steam ${ }^{9}$ often betray these kinds of views. 'I need to know if the dev[eloper] is a feminist/sjw [social justice warrior]' begins one; 'I have no problem with women developing games, what I do have a problem with is self entitled whiney 00000 es who have no interest in video games at all forcing their way into my hobby and pushing their dumb 0000ing agendas'. ${ }^{10}$ Other reviewers, while taking pains to distance themselves from gamergate's overt misogyny ('I want female developers to succeed because their gender should make no difference'), complain that Cibele is 'barely even a game', ${ }^{11}$ reflecting a preference among many "hardcore" gamers for titles that function primarily as systems for sorting winners from losers, rewarding those with 
the dexterity and strategic nous (not to mention the technological knowhow, specialist hardware and familiarity with generic conventions) necessary to triumph. Foregrounding the gameness of videogames, these criteria pointedly exclude story-led slices of life like Cibele, while also calling into question the validity of the many videogames perhaps better described as audiovisual toys, digital construction sets, relaxation aids, virtual pets, interactive picturebooks or frameworks for social bonding than games per se. In so doing they help to legitimize and reproduce the familiar image of the "real" gamer as an able-bodied, economically advantaged young white man.

Here, as Aubrey Anable insists, the discipline of game studies must bear some responsibility. Keen both to affirm the medium's uniqueness and to defuse alarmist accounts of violent games turning kids into killers, many early videogame scholars downplayed videogames' representational qualities, favouring formalist analyses of games as procedural systems. ${ }^{12}$ For Anable, this left scholars poorly equipped to counter gamergate's refusal to countenance 'feminist critique on the grounds that games should be evaluated not as representations but rather as playful and apolitical systems', while entrenching the idea that videogames focused on strategy and simulation are somehow more legitimate than those concerned with telling stories, facilitating creativity, exploring ethical dilemmas or eliciting particular emotional states. ${ }^{13}$ Rejecting this 'gendering' of the medium along a 'computation/representation' axis, Anable proposes an understanding of gameplay as a means of 'giving colour, rhythm, shape and sound - a texture and tone-to time spent with computational systems', identifying gaming culture as a key site for the production of 'contemporary subjectivities'. ${ }^{14}$

These are functions that Freeman's games-concerned as they are with how play feels and how it facilitates the formation of relationships and identities-both perform and reflect upon. Those games range in style, tone and mechanical complexity, assuming forms tailored to the situations they address. The microgame how do you Do It? , for example, draws on Freeman's memories of how, as a seven-year-old fascinated by the sex scenes in Titanic, she would 'play house with my Barbie dolls... bang[ing] together their plastic bodies... as if they were having sex'. The game gives players 50 seconds to create as many configurations as possible with two naked dolls. ${ }^{15}$ Ladylike sees 12-year-old Nina chafing against her mother's maddeningly narrow notions of appropriate feminine behaviour, asking players to select dialogue options that advance a prickly mother-daughter conversation. Lost Memories Dot Net, 'a game about chatting and building websites as a teenage girl in 2004', is a prequel of sorts to Cibele, and has Nina negotiating a middle school love triangle while beginning to 
write about herself online. Freshman Year addresses Freeman's experience of being sexually assaulted by a bouncer while waiting to meet a friend at a bar while in college. Other games look beyond Freeman's biography while exploring similar themes: the Wellcome commission Table Talk uses a 1915 Frederick Cayley Robinson painting as the basis for an interactive fiction about friendship, gossip and puberty; the young heroine of Kimmy spends the summer of 1968 babysitting a troubled younger girl. Like Cibele, it foregrounds the sociability of play.

Freeman's games reject the principle that by discovering the correct sequence of choices or actions players should be able to "win". Their outcomes are usually predetermined, and are seldom unequivocally happy. Indeed, they are seldom unequivocally anything, tending toward irresolution and ambivalence. If the field of game studies has long debated whether the idea of 'interactive narrative' is a contradiction in terms, ${ }^{16}$ this question becomes especially pointed in the case of autobiographical games. In most of Freeman's games the player's ability to shape Nina's fate is strictly limited. This is not just a matter of maintaining fidelity to Freeman's experiences, but also of conveying the tenor of the lose-lose situations she portrays: the mother in Ladylike is literally impossible to please because the demands made of girls are at once so exacting and so contradictory; the assault in Freshman Year can't be averted because Freeman rejects the victim blaming so prevalent in discussions of sexual abuse. In all videogames, even those advertised as offering experiences of empowerment and wish fulfilment, the player's freedom to act is predicated on their submission to hard-coded rules; Freeman's games use this fact to foreground the forces that shape young women's lives, from social etiquette and technological literacy to patriarchal violence.

These concerns inform both Cibele's content and its structure. The game is about Nina's bid to shape a self flexible enough to survive the male-dominated spaces of online gaming culture while meeting the paradoxical demands of postfeminist culture. But it also constitutes Freeman's attempt to craft a suitable vehicle for her teenage experiences-and, more specifically, to give an account of those experiences that challenges moralizing and scaremongering discourses about the dangers facing young women who seek intimacy on the internet. Autobiographer and protagonist alike employ bricolage and aesthetic excess as means of achieving these goals. Like Nina's online self, Cibele is an assemblage: part digital archive, part miniature autobiopic, part videogame. Such hybridity befits

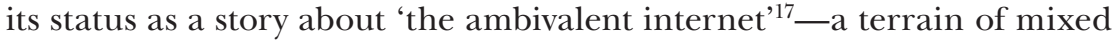
feelings, opaque motives and competing viewpoints in which irony and pastiche can be hard to separate from deadly serious sincerity. Nina's self-presentation strategies-and particularly, as I want to propose, her 
cultivation of a kind of highly stylized kawaii ${ }^{18}$ femininity—manifest her own mixed feelings but also represent attempts to anticipate and manage how others might perceive her. She draws on a range of materials and discourses to craft a polysemous persona that, depending on the perceiver's point of view, vacillates between the poles of naïvety and knowingness, sexual subjecthood and sexual objecthood, irony and candour. Freeman, meanwhile, pointedly departs from the narrative conventions and prescriptive biases typical of accounts of online girlhood, asking players to recognize and question these orthodoxies.

\section{NARRATING NETWORKED LIFE}

Structurally, Cibele is broken into three acts. Each alternates between non-interactive video scenes in which Freeman plays her younger self and sequences in which players are afforded a Nina's-eye-view of her computer screen (Figure 1). Nina's desktop is littered with folders containing photos, poems, archived blog layouts and journal entries, allowing players to track her evolving tastes, personal style and autobiographical voice. These materials-many drawn from a trove of 'files and chat logs Freeman found on her old hard drive ${ }^{19}$ — help to establish where Nina stands at the point the game opens. They reveal that she's 18 , has never had a sexual relationship, loves videogames, manga and anime, and has already been sharing her life online for at least six years. From her desktop we can also boot up Valtameri, the game-within-a-game through which Nina interacts with Blake (known online as Ichi), the 23-year-old who will break her heart. Valtameri is framed as a massively-multiplayer online roleplaying game (MMORPG) along the lines of Final Fantasy XI, the game in which Freeman's real-life romance developed. Freeman radically abstracts this model, however, reducing play to a matter of clicking in the direction we want Nina's avatar to move and then clicking on enemies to vanquish them. At no risk of dying, players are free to listen to the conversations Nina and Blake have as they play, and to keep up with the messages and pictures Nina exchanges with her friends and fellow gamers. By removing the other dimensions of their gameplay Cibele foregrounds what is, for Freeman at least, the key aspect of MMOGs: their status as spaces in which 'to play and chat with your friends' in such a way that 'the game becomes the mediator of all your relationships with the people there. ${ }^{\prime 20}$

As Cibele progresses Nina and Blake begin messaging more frequently, trade increasingly racy selfies and eventually arrange to meet in the flesh. At this point, we might expect a dramatic twist in the tale. As Amy Shields Dobson notes, contemporary culture is rife with narratives 'about the internet as a "paradise" for stalkers and would-be sexual criminals, and 


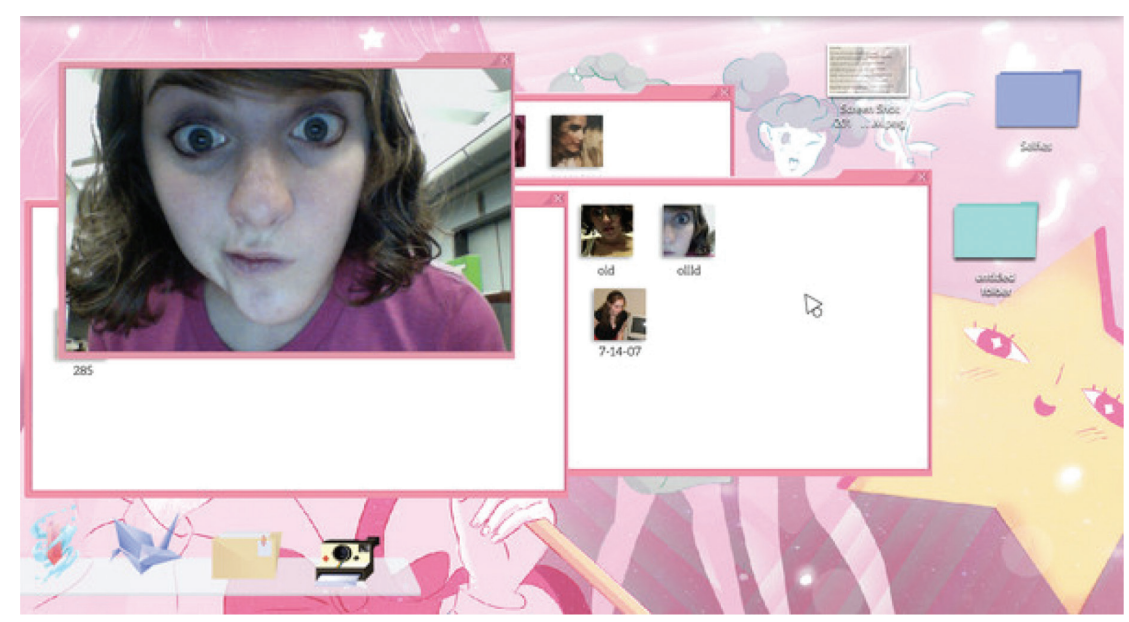

Figure 1. Nina's desktop (image Star Maid Games).

about young women's employment of SNSs [social networking sites] for... sexualized self-representation'21; primed by such accounts, it is easy to assume that Blake will turn out to be a "catfish", ${ }^{22}$ a criminal, a pornographer or an identity thief. In fact, he is none of these things-but nor is he Mr. Right. The two meet and have sex, a first for both. But Blake-who has, in earlier conversations, declared himself uncomfortable with the idea of entering into a relationship-apologetically concludes that their meeting was a mistake, and that he doesn't really love Nina. If the game's lack of last-minute twists or life-changing consequences is, one assumes, true to Freeman's actual experience, it also serves as a counterpoint to the kinds of narratives Dobson describes, narratives that usually conclude with moralising come-uppances, punishing women who, by "oversharing" (a nebulous and, as Sykes argues, ${ }^{23}$ highly gendered term), supposedly mark themselves out as naïve, lazy or vain. For Wendy Chun, such stories bespeak a desire for scapegoats onto whom privacy concerns can be pinned ${ }^{24}$ Dobson, meanwhile, compares their 'linking of online sexual self-representation to risk of predation, abuse and violent crime... to the kind of victim blaming that goes on in relation to other sex crimes, where the victim's clothing choices and behaviour are assessed and judged in terms of their ability to "provoke" violence from men'. ${ }^{25}$ As I have noted, Freeman has directly addressed this mentality in another autobiographical work, Freshman Year. That game gives the player several choices-which outfit to wear, whether to wait for Nina's friend inside or outside the club, how to respond to the flirtatious remarks of the bouncer who attacks her 
and so on. Upon replaying it however (a process that takes no more than a few minutes), it becomes apparent that our choices make no difference to how the assault plays out. If Freshman Year limits the player's agency in order to challenge victim-blaming rhetoric, Cibele does so in part to show how this 'victim-blaming mentality' is 'continued... into digital realms'. ${ }^{26}$

Once it becomes clear that Cibele is not a parable about the dangers awaiting young women online it becomes possible to appreciate the game for what it is: a story about networked intimacy, the relationship between digital and material spaces, and the ways in which gendered identities are performed in and across those spaces. Living on opposite coasts, Nina and Blake use Valtameri to achieve a form of intimacy at a distance. While they are constrained by technological limitations, Blake, in particular, finds these constraints enabling. He tells Nina that he hates 'leaving my security zone' to interact 'in person', describing himself as 'less antisocial, more anti-connection'. For him, online games provide relief from feelings of being over-embodied or affectively swamped: he finds it 'easy to talk when you're not looking at someone', telling Nina 'you're way too hot, I wouldn't even be able to breathe near you in real life.' It is Nina who insists that they need to meet 'face-to-face' to clarify what's going on between them, reasoning 'we love each other... [and] that's not just in the game'. When they do meet, though, Blake finds that he would rather retreat back to his computer.

Blake's reaction resonates with Robyn Warhol's discussion of how digital communications technologies reflect and entrench dominant gender norms. Drawing on an autobiographical essay by coder Ellen Ullman, ${ }^{27}$ Warhol notes that in a culture where intimacy and emotional availability are coded as 'effeminate' it is hardly shocking that a male-dominated computing industry should have devoted so much effort to finding ways of bringing others closer without letting them get too close. Computers allow users to circumvent face-to-face interaction and maintain the kind of 'lonesome' self-sufficiency central to myths of masculine autonomy and stoicism. ${ }^{28}$ Blake's statements also hark back to 1990s fantasies of "cyberspace" as a realm where users can escape their fleshly bodies and craft new identities. As scholars have long argued, such fantasies are rooted in the very material realities they aspire to transcend: to the extent that these dreams of protean pseudonymity came true, they did so primarily for white middle-class males and those able to pass as such. ${ }^{29}$ That the internet represents a 'security zone' for Blake is, in short, indicative of the demographic privileges he enjoys. For Nina it is neither possible nor desirable to maintain a strict separation between online and offline existence. She too is shy and awkward, but in her case these feelings are a spur to share more of her life, her identity, and, importantly, her gendered body-affirming 
Theresa Senft's observation that 'so-called "shameless"' online behaviour is often a means of 'easing feelings of shame' ${ }^{30}$ If Cibele is about Nina's relationship with Blake, it is also about her more or less extended, intense and passionate relationships with the various media, platforms and devices she uses to construct a networked identity, from text and photography to emoji-like "emotes" and Skype-style voice call software.

At the time of Cibele's opening Nina has recently posted a photo of herself to the Valtameri forums, meaning fellow players who had only known her through her in-game avatar Cibele ${ }^{31}$ now know what she looks like. Many female gamers would consider such openness unwise or excessive. Women who play MMORPGs commonly receive misogynistic abuse and unsolicited sexual overtures, not to mention 'special attention, help, or gifts' from 'male players assuming that if they give us stuff, we'll be their girlfriends or send them naked pictures' ${ }^{32}$ As a consequence, they are forced to develop 'ways of using and relating to their gender': ${ }^{33}$ some play up to normative notions of femininity 'in order to gain items or help'; others 'fight, literally, for the right to be treated equally'; others still remain silent or intentionally misrepresent themselves in order to deflect unwanted attention. ${ }^{34}$ Such accounts help to contextualize Nina's experiences as a woman considered 'hot' and 'cute' by male players. When Nina observes that Blake never seems to criticize her like he does the other members of their group, he replies 'I'm not gonna yell at a cute girl', substantiating GuyverGuy's claim that Blake goes easy on Nina because 'ur a girl and he thinks ur hot'. Later, when Nina asks Blake whether she is good at the game, he replies that she's not just 'way better [at Valtameri] than other girls' but also 'sexy and smart'. Freeman shows Nina, Blake, and their fellow Valtameri players to be bound together in a metagame with its own complex economy. Here affirmation, titillation, trust, advice and gossip circulate alongside virtual and physical goods, and women are encouraged to attain leverage by sharing selfies that function as 'bearers of "corporeal capital". ${ }^{35}$ While the photo Nina takes for Blake at the end of Cibele's first act is the game's most noteworthy example of this dynamic, other instances of Valtameri players sending or soliciting such images abound: Rusher refers to a baseball jersey he has given Nina, asking whether she'll send him a shot of herself wearing it; firesss, with whom Nina once 'had a thing', forwards a risqué selfie of hers to GuyverGuy, apparently to get back at Nina for having moved on to Blake; Blake confesses to having received photos from a girl Nina worries is 'cooler' than her. Assuring her 'your face is way nicer' he reaffirms that Nina's main asset, at least in his eyes, is corporeal capital rather than coolness or gaming skill. Other female players, meanwhile, criticize Nina for posting a forum photo that they think emphasizes her 'boobs' too much. 
While Nina claims that she posted her forum photo 'in a moment of vanity', her file and folder names ('forum', 'forumpic', 'forichi', 'forU', 'mehmaybe', 'better', 'cutewow', 'bwtest') suggest that she carefully considers which pictures she should share and with whom, scrutinizing and appraising images of her body before submitting them to the judgment of third parties. Given the degree of (mostly undesired and unsought) male attention she receives, her claim that Blake is 'the only guy on earth' who considers her 'hot' might sound disingenuous. But it also speaks to what Freeman portrays as Nina's deep-seated discomfort with her body. At the same time she is creating ever more revealing images 'for ichi' (to the point, as her chatlogs show, of buying and borrowing lingerie and swimwear to pose in) Nina is confessing in conversations with female friends to 'feeling gross. like I look gross'. But while we might see the images Nina creates and shares as nothing more than evidence of her being needy and naïve, Freeman seems to share Tiidenberg's desire to question the idea 'that sexy selfies cannot be anything but a postfeminist glorification of internalized objectification'. ${ }^{36}$ If nothing else, she proves keenly aware of the contradictory demands in response to which young women's online self-presentation strategies develop. As the next section will argue, Cibele presents Nina's approach to self-branding as both a product of and a response to 'the ambivalent internet': a space where the impossibility of determining 'who is participating, who is observing, and what sets of assumptions each person brings to a given interaction' has given rise to polysemous modes of expression which 'could go either way, in fact could go any way simultaneously', abandoning the logic of 'this as opposed to that' in favour of an aesthetics of 'both'. ${ }^{37}$

\section{OTAKU AESTHETICS}

Here it pays to attend to a word that recurs throughout Cibele: "cute." For Sianne Ngai, cuteness expresses the ambivalences at the heart of commodity culture. The term infantilizes even as it eroticizes; it 'is a way of sexualizing beings and simultaneously rendering them unthreatening', and while the cute object's formlessness and helplessness might elicit instincts toward 'protection and care', these feelings are, Ngai advises, seldom without their alloy of sadistic aggression. ${ }^{38}$ For Cibele's cast of socially awkward, sexually inexperienced teens and twentysomethings the word has multiple virtues, allowing them to cultivate ambiguity and express mixed feelings; safely innocuous, it is also capable of encompassing morethan-platonic possibilities. 
The cuteness Nina cultivates is informed by her love of Japanese pop culture, known for its own subset or strain of the cute: the kawaii. Wideeyed anime and manga heroines adorn her walls and her desktop, while her hard drive is full of blogposts and fan art attesting to her longstanding love of media about "magical girls" battling to rid the world of evil. Nina's engagement with these texts parallels the modes of 'brand[ing] the self' practiced by the young women Dobson studies, whose online profiles are often decorated with what she dubs " dream girls icons"... cartoons, animations, and digitally rendered or digitally altered' images of 'heterosexy' female bodies. ${ }^{39}$ For Dobson, such images provide a means of negotiating the complex dynamics of sexual objecthood and subjecthood online: on the one hand, the presence of such images on a personal profile might suggest that the figures depicted are to be understood as 'standing in for the profile owners themselves' in a gesture of 'identification with objectified women'; on the other, these images can be interpreted as 'imagery consumed or liked by the profile owners', serving as sexualized objects in relation to whom those profile owners can manifest a kind of sexual subjectivity, performing 'complicity and self-alignment with a historically male, heterosexual gazing subject position'. ${ }^{40}$ In a postfeminist culture which expects young women to be sexually liberated but not "too" promiscuous, in online spaces where to present as a woman is to leave oneself open to uninvited sexual advances, these images offer a means of coding oneself as 'hot' and sexually savvy but not necessarily 'up for it' or 'sexually available to viewers', of 'agentically engaging with the aesthetics of femininity and heterosexy consumer culture in a way that is signalled as both playful and authentic'. ${ }^{41}$

A similar tension between identification and objectification marks Nina's relationship with anime iconography. ${ }^{42}$ As she asserts in a chat with Rusher, 'i always do my best to look anime ${ }^{\wedge} \_\wedge$ '. But Nina also aligns herself, however ironically, with male consumers of sexualized kawaii imagery-not least through her ownership of a dakimakura or 'love pillow'. Commonly decorated with female anime characters in sexually suggestive poses, dakimakura are associated with the phenomenon of "2D love", whereby male otaku ${ }^{43}$ forego human relationships in favour of onanistic devotion to cute fictional characters and the commodities through which they attain tangibility. The dualities that Nina uses Japanese pop aesthetics to navigate-innocent/knowing, subject/object, familiar/foreign, desiring/desirable-are crystallized in the image she creates for Blake at the end of chapter one (Figure 2). Her peace $\operatorname{sign}^{44}$ and her candy-coloured hair reference the playful innocence of anime heroines like Sailor Moon; her aloof expression and lacy pink bra (the same shade as her dyed hair) hold out the prospect of sexual availability while projecting sexual agency. 


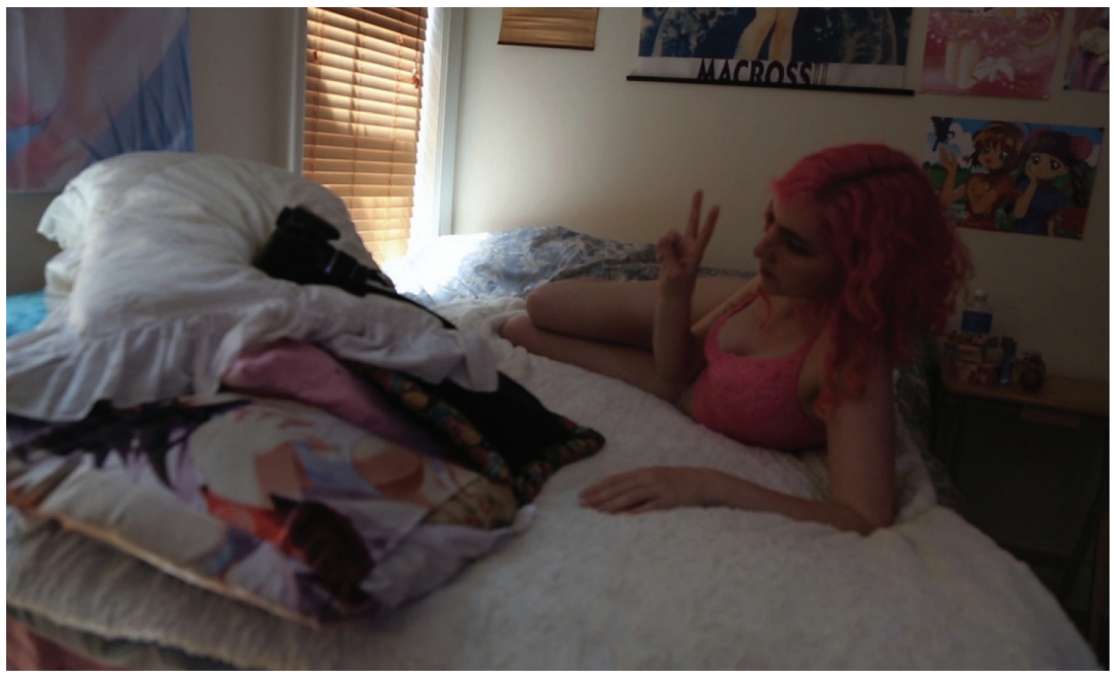

Figure 2. Nina posing for a photo for Blake at the end of Cibele's first act (image Star Maid Games).

It is important to consider geography and ethnicity alongside gender here. The fact that Japanese texts featuring kawaii heroines can be read as 'feminist' or 'sexist' ${ }^{45}$ only makes them more resonant for young women who, whether North American or Japanese, face 'multifarious pressures... to present their bodies as objects of consumption' while aspiring to 'corporeal and sexual subjectivity as conscious and empowered agents' ${ }^{46} \mathrm{But}$, as Makiko Iseri insists, while 'modes of feminine gender performance in Japanese girls' culture' often 'look, at first glance, quite similar' to the forms of 'hyperfemininity' prevalent in contemporary Euro-American girl culture, their particular position 'within the complicated power structures of neoliberalism, Orientalism and nationalism' should not be forgotten-especially when we are addressing how these styles have been received and adopted by white women outside Japan. ${ }^{47}$ For Iseri, Japan's embrace of kawaii aesthetics represents the 'strategic incorporation of an Orientalized image of Japanese inferiority/immaturity'. ${ }^{48}$ Ngai concurs, relating kawaii to the situation of 'a post-World War II Japan... newly conscious of its diminished economic and military power'. ${ }^{49}$ Like otaku culture in general, kawaii style is a source of both pride and shame in Japan $;^{50}$ while its grip on global pop culture provides an index of Japanese 'soft power', for some it signifies an erstwhile empire's emasculating metamorphosis into a purveyor of cutesy trifles. 
Once we acknowledge this, Freeman's portrayal of Nina's kawaii selfbranding strategies becomes highly complex. Nina's efforts to 'look anime' suggest a longing for an identity as cogent and immutable as a cartoon character's, a desire to be an image or a thing rather than an embodied subject (indeed, this may be what attracts Blake to Nina). They also render her less legible, however, allowing her to hover between being read as guilelessly girlish or as knowing enough to ironically cite and affectionately travesty kawaii hyperfemininity. Nina's knowledge of Japanese pop culture and her extensive collection of media and merchandise give her a degree of subcultural prestige among certain North American fan communities. But these texts and commodities also offer means of expressing how impotent, infantile and out of place she feels. And while such feelings are hardly uncommon in late adolescence, Freeman's Twitter profile (with its pink palette, its flowers, hearts and selfies and its cutebut-carnal banner image of a buxom hentai ${ }^{51}$ heroine) shows that she continues to find these anime-inflected aesthetic strategies enabling as a grown-up game designer with a massively expanded public profile. While Freeman's investment in otaku culture is undoubtedly genuine, in a culture where 'kawaii' signifiers have been accommodated into the performative repertoire of the 'Instagirl', ${ }^{52}$ questions of white privilege, and of where exactly identification and appreciation shade into appropriation and exoticisation, demand attention. As I have argued elsewhere, ${ }^{53}$ such questions are never far away when we are discussing the Euro-American reception of Japanese pop culture; but they are perhaps especially pertinent when considering media that, for Iseri and Ngai, are the result of Japan's culture industry cannily playing up to stereotypes of Japanese eccentricity, disempowerment and juvenility.

\section{CLOSING THE GAP}

Freeman's engagement with otaku culture also has important implications for how we understand Nina and Blake's relationship-and, by extension, the game's framing of the relationship between online and offline space, embodied and computer-mediated interaction. The fact that Blake and Nina's romance founders when they meet in person might suggest that the weight of embodied co-presence is too much for it to bear, confirming that it was insufficiently grounded in reality. While this interpretation is not wrong per se, Freeman also leaves room for a slightly different reading. Here Eva Illouz's work-which distinguishes between online and offline romance, but not on the terms we might imaginebecomes useful. Addressing the fact that online dating sites seem to have made falling in love more difficult, Illouz proposes that they offer 'too 
much information', 'defining subjects as entities endowed with discernible, discrete and even quantifiable attributes' ${ }^{54}$ By comparison, offline encounters are 'information-thin'; yielding only 'an incomplete and intuitive knowledge of another person', they leave more room to draw on our 'unconscious knowledge' and invest the other's 'words, bodily gestures and motions, inflections of the voice' with meaning via a 'process of idealization'. ${ }^{55}$ Whether we understand this process in 'psychological and biographical' terms (as Freud would) or in terms of 'social and collective' codes and patterns of association (as Illouz prefers to), the point remains that offline romance is not necessarily any more or less "real" than online dating; both entail imaginative projection and, if anything, offline encounters involve more 'over-evaluat[ion]' and extrapolation. ${ }^{56}$ In the years since Illouz's analysis so-called "hook-up apps" like Grindr and Tinder have retooled networked romance for the smartphone era, addressing some of the issues she highlights. Launched in 2009, Grindr used geolocation technology to let users share photos and profiles with fellow gay and bisexual men in the area. Tinder followed in 2012, successfully expanding this idea to the heterosexual demographic while introducing a much-imitated swipe interface: users swipe right if they want to meet and left if they don't. Privileging geographical proximity over personality type, values or shared interests while circumventing deliberation by soliciting split-second yes or no responses, these services use smartphones' affordances (GPS, WiFi, touchscreens) to elicit decisions that are less informed and more intuitive than those of bygone online daters. In so doing they underscore the folly of opposing a material world grounded in reality to a digital realm in which fantasy and imagination are given freer rein.

Rejecting this dichotomy allows us to rethink what Blake and Nina's single embodied encounter-an encounter that consummates but also concludes their relationship-says about the months of mediated contact that have preceded it. It is tempting to see the fact that their romance doesn't survive their face-to-face meeting as a sign that theirs was never "real" love. Illouz, however, troubles this assumption by insisting that immediate access to the other is always impossible-even (if not especially) when the two parties meet "IRL" ${ }^{57}$ With this in mind, it becomes possible to see the media Nina and Blake exchange as something more than partial, piecemeal substitutes for the other's material presence. For much of the game Blake only exists as images, messages and audio, for the player as for Nina (whose offline life we do at least glimpse, and from whose perspective we see things). But Freeman implies that Nina establishes a genuine connection with the Blake she synthesizes out of these materials. Such a stance would be entirely in keeping with the way that 
Saito Tamaki has characterized otaku culture. For Tamaki, the otaku's passionate investment in representations that have 'no referent in reality' and their ability to discriminate between 'multiple levels of fictionality... has made them better equipped to cope in a media-saturated postmodern society in which the distinction between fiction and reality is increasingly problematic', ${ }^{58}$

This is not, however, to allege that offline romance and online romance, 2D love and 3D love, can be conflated because they all occur 'in the mind'. It remains crucial to look beyond the individual subject's psyche, addressing the cultural factors Illouz highlights, but also the materiality of subjects' bodies-and of the technological assemblages to which those bodies are connected. If this necessity is already acknowledged to some extent in the Lacanian media theory on which Tamaki draws, ${ }^{59}$ much recent work on digital culture has turned to affect theory and posthumanism in the attempt to account for the entanglement of human and nonhuman actors online. Emma Leigh Waldron, for example, argues that contemporary forms of mediated intimacy call for 'a more expansive definition' of sex: beginning from the position 'that sex is not always or only about reproduction (as feminist theory has shown), and that it is not always or only about two-bodied, heterosexual, genitally-focused, or orgasmic pleasure (as queer theory has shown)', Waldron proposes that online activities which bring 'bodies (human and otherwise) into pleasurable, intimate, and caring proximity' can be considered sexual ${ }^{60}$ From such a perspective Nina's is not just a relationship mediated by technology (which would imply that the relationship predates or can be separated from its mediation) but a relationship with the software and hardware doing the work of mediation.

Questions as to whether Nina's relationship with Blake qualifies as "real love" are also questions about what counts as "real life"-and as suitable subject matter for life writing. Does time spent playing videogames, Skyping, creating fan art or taking selfies merit inclusion in an autobiography? On what terms? While nearly everyone now writes about their lives online, the question of how to write about our online lives remains a tricky one. Certain biographical forms have long focused on what happens in the mind or on the page, but there is still a tendency to see much screen-centric activity as inconsequential. Cibele doesn't just question this privileging of the embodied and the immediate over the virtual and the vicarious; it suggests that, for otaku who grew up online, such distinctions make little sense. For Tamaki, otaku recognize that "Imaginary objects exist right alongside our perception of "everyday reality," and... are no less "real" in terms of their psychic effect on us. ${ }^{61}$ We can hear an echo of this sentiment in Cibele's closing statement: 'First love is a confusing 
thing, and sometimes it really hurts, but I'm glad I had mine with you.' Where we might expect the older, wiser Freeman to accept that what she experienced with Blake was not actually love, she insists instead that her relationship was no less genuine, formative or painful for having mostly played out online, offering an example of how (in Anable's words) 'games make complex meanings across history, bodies, hardware and code. ${ }^{62}$

This final statement, preceded by a shot of Nina back in her room, alone, is as close as Cibele comes to an epilogue. Many players have declared themselves unhappy with the game's conclusion. Steam user reviews call it 'laz [y], disappointing and uninspired' ${ }^{63}$ 'abrupt and poorly conceived' ${ }^{64}$ or just 'terrible', complaining that 'a lot went unsaid and unexplained'. 65 Many players seem galled by the lack of an overt moral; replying to a review that observes 'I honestly thought the game was shaping up to be a cautionary tale to tell naïve girls not to talk to creeps online', ${ }^{66}$ Steam user A Dolphin argues that Freeman's failure to explicitly frame Blake as a 'creep' and a 'pickup artist' is irresponsible, and shows that she 'learned nothing' from the experiences she recounts ${ }^{67}$ Even journalist Katherine Cross-who writes approvingly that Cibele 'does not give us answers because Nina Freeman... does not have them, merely a bit of hard won wisdom and experience'-criticizes the game's ending for being 'abrupt and unsatisfying, ${ }^{68}{ }^{6}$ Such comments confirm that, at least for some players, Cibele's lack of a twist, or of a fuller attempt at resolution or reflection, is experienced as a twist in its own right. Few critics, however, entertain the idea that this effect might be intentional, a way of responding to the hysteria and hyperbole that surround young women's online practices, or of handling memories that elicit mixed feelings. Instead, reviews reflect the ongoing tendency to understand works of female self-expression as 'spontaneous' outpourings rather than 'crafted' products of reflection, routinely conflating autobiographical teller and protagonist. ${ }^{69}$ Reviewers compare the game to selling one's diary ${ }^{70}$ imply that Freeman remains too naive to really understand the events she represents (and/or too inept to shape them into an insightful narrative) and accuse her of using screenshots of herself 'doing... assorted things in her underwear' to sell her game. ${ }^{71}$ Others, as we have seen, are more openly misogynistic, reflecting videogame culture's position as a key battleground in what many view as a 'new culture war.' 72

Such comments demonstrate the discursive mechanisms mobilized to turn the female life writer into what Leigh Gilmore calls a 'tainted witness': Freeman is 'discredited', her capabilities as a storyteller are called into question and she is framed as 'the greedy purveyor [of] her own sexiness and story... the exploiter of her experience for profit'. ${ }^{73}$ Gilmore argues that especially intense hostility and suspicion are reserved for 
autobiographers who depart from the dominant model of the "neoconfessional... redemption narrative', refusing to assume the role of 'victim' or 'criminal'. ${ }^{74}$ Consciously eschewing the alarmist tone of much discourse around networked intimacy in a way that, for some players, signifies her failure to recognize herself as a victim, Freeman marks herself out as just such an 'insufficiently redeemed' narrator. ${ }^{75}$ Cibele gives few indications as to whether she feels fondness or admiration, exasperation or pity for her (marginally) younger self, and is similarly noncommittal with regard to what we might learn from Nina's story. It suggests that online indiscretions don't necessarily end in tragedy, that young men don't have to be cynical manipulators or criminal impostors to handle sexual relationships badly or treat women poorly, and that posting sexy selfies can have unintended consequences but can also be a means of self-fashioning.

In many ways Freeman's aversion to explanation and prescription is, like Nina's cultivation of a knowingly hyperbolic kawaii femininity, consistent with the ethos of so-called "third wave" feminisms. While the wave model of feminist history has many drawbacks ${ }^{76}$ it is helpful here both in illuminating what Cibele shares with its predecessors and how it differs from them. For while the game inherits the third wave's emphasis on plurality and hybridity, its preoccupation with questions of identity performance, objectification and empowerment, and its willingness to acknowledge, and even celebrate, contradictions, paradoxes, and ambiguities ${ }^{77}$ Cibele is notably lacking in the optimism and idealism that animated many third wave texts. Irony, pastiche and an aesthetics of 'both' once seemed capable of subverting ossified identity categories and accommodating those alienated by the ideological 'stringen [cy]' of second wave feminisms $;{ }^{78}$ for Nina, however, the appeal of these strategies is more pragmatic. Where many 1990s feminists drew on constructivist philosophy and invoked the apparent promise of nascent cybertechnologies to affirm the liberatory potential of self-fashioning and semiotic play, Nina's online persona is not freely constructed so much as it is carefully calibrated to maximize her chances of approval, factoring in the affordances and constraints of the technologies available to her and the degree of corporeal capital she possesses as a 'cute girl'. Where some third wavers worried that 'although postmodern irony functions subversively for select audiences, it may well function hegemonically for others' ${ }^{79}$ for Nina this is arguably its advantage. In this sense Cibele might be seen as illuminating third wave feminism's mutation into the regressive, politically inert forms of 'post-Feminism' that, for McRobbie,${ }^{80}$ it inadvertently laid the groundwork for.

Dispiriting as this may be, Cibele is also proof that digital technologies really have fostered new forms of, and forums for, women's life 
writing-albeit not on the terms 1990s internet evangelists might have hoped. Nina's experiences as a gamer, like Freeman's as a game designer and digital autobiographer, show how media scaremongering and the machinations of platform holders operate in tandem with everyday misogyny and sexism to deter and devalue female participation in digital spaces. They also bear out Schwarz's argument that our eagerness to frame 'new technologies of self-documentation as emancipating' can blind us to how 'audience expectations, the logic of fields, [and] market demands' inform their usage. ${ }^{81}$ For many players, Cibele's engagement with these issues was too tentative, oblique and solipsistic. These ostensible failings assume a different aspect, however, if we see Freeman as remediating the autofictional approach Sykes identifies with authors like Chris Kraus, whose novel I Love Dick is often seen as the catalyst for the forms of 'Lonely Girl Phenomenology' practiced by Dunham, Heti et al. ${ }^{82}$ Like these authors, Cibele offers a record of 'women's experience that is indelibly white, middle-class, and heterosexual'; as in their work, however, there is a sense in which this 'narrowness' of perspective is inseparable from the game's 'artistic vision', performatively highlighting the impossibility of speaking candidly about the mundane realities of sex, gender and identity without being framed as brazen, invidious, suspect and/or mercenary. ${ }^{83}$ From the paradoxes of postfeminism and the imbrication of shame and "shamelessness" to the dynamics of online subcultures, Cibele shows there are subjects about which one can only say too much and too little.

Of course, there are limits to what such an autofictional approach can achieve, and works like Kimmy-in which Freeman looks beyond her own life and times to addresses the experiences of a demographically diverse cast navigating the realities of bigotry and inequality in a civil rightsera US town-suggest that this 'narrowness' may be beginning to chafe. Which is not to suggest that Kimmy represents a radical about turn or an implicit mea culpa; drawing on Freeman's mother's childhood memories of 1960s Massachusetts, Kimmy is, like Cibele, an intentionally understated, unapologetically cute game about young women seeking connection through play as they learn to name and negotiate the social forces that will shape their lives.

\section{ACKNOWLEDGEMENTS}

The research leading to these results has received funding from the European Research Council under the European Union's Seventh Framework Programme (FP7/2007-2013)/ERC grant agreement no. 340331. 


\section{WORKS CITED}

A Dolphin. "Comment on Kinggimped's Review of Cibele." Steam 2016. http://steamcommunity.com/id/facialist/recommended/408120/. Accessed 23 Oct. 2017.

Anable, Audrey. Playing with Feelings: Video Games and Affect. Minneapolis: University of Minnesota Press, 2018.

A Normal Lost Phone. Developed by Accidental Queens, 2017.

Azuma, Hiroki. Otaku: Japan's Database Animals. Minneapolis: University of Minnesota Press, 2009.

Bee. "Review of Cibele." Steam 2016. http://steamcommunity.com/id/Speedette/recommended/408120/. Accessed 23 Oct. 2017.

Brehm, Audrey L. "Navigating the Feminine in Massively Multiplayer Online Games: Gender in World of Warcraft." Frontiers in Psychology 4 (2013): 1-12.

Chun, Wendy Hui Kyong. Updating to Remain the Same: Habitual New Media. Cambridge, MA: MIT, 2016.

Cibele. Developed by Nina Freeman/Star Maid Games, 2015.

Coulter, Charles Russel and Patricia Turner. Encyclopedia of Ancient Deities. London: Routledge, 2012.

Cross, Katherine. "How Cibele Taught Me to Love Existential Sex Crises." Gamasutra 2015. https://www.gamasutra.com/view/news/258896/How_Cibele_taught_me_to_love_existential_sex_crises.php. Accessed 23 Oct. 2017.

Dicker, Rory, and Alison Piepmeier. "Introduction." Eds. Rory Dicker and Alison Piepmeier. Catching a Wave: Reclaiming Feminism for the $21^{{ }^{t}}$ Century. Boston: UP of New England, 2003. 3-28.

Digital: A Love Story. Developed by Christine Love, 2010.

Dobson, Amy Shields. Postfeminist Digital Cultures: Femininity, Social Media and Self-Representation. New York: Palgrave Macmillan, 2015.

Dys4ia. Developed by Anna Anthropy, 2012.

Ed0022. "Review of Cibele." Steam 2017. http://steamcommunity.com/id/ed0022/recommended/408120/. Accessed 23 Oct. 2017.

Eklund, Lina. "Doing Gender in Cyberspace: The Performance of Gender by Female World of Warcraft Players." Convergence 17.3 (2011): 323-342.

Final Fantasy XI. Developed by Square, published by Sony Computer Entertainment, 2002.

Freshman Year. Developed by Nina Freeman/Star Maid Games, 2015.

Gallagher, Rob. "From Camp to Kitsch: A Queer Eye on Console Fandom." GAME: The Italian Journal of Game Studies 1.3 (2014): 39-50.

Gilmore, Leigh. Tainted Witness: Why We Doubt What Women Say About Their Lives. New York: Columbia UP, 2017.

Gustainis, J. Justin. "Peace sign/Peace Symbol." Ed. M. Paul Holsinger. War and American Popular Culture: A Historical Encyclopedia. Westport: Greenwood Press, 1999. 408.

Gwynne, Joel. "Japan, Postfeminism and the Consumption of Sexual(ised) Schoolgirls in Male-Authored Contemporary Manga." Feminist Theory 14.3 (2013): 325-343.

'Hentai.' Oxford English Dictionary. $3^{\text {rd }}$ ed., 2011.

how do you Do It? Developed by Nina Freeman/Star Maid Games, 2014.

Hudson, Laura. "Cibele is a Crazy-Real Game about Falling in Love Online." Wired 2015. www. wired.com/2015/11/cibele-game-nina-freeman. Accessed 29 September 2017.

Illouz, Eva. Why Love Hurts. London: Polity, 2012.

"IRL." Oxford English Dictionary. Draft addition, 2016.

Iseri, Makiko. "Flexible Femininities? Queering Kawaii in Japanese Girls' Culture." Eds. Claire Nally and Angela Smith. Twenty-First Century Feminism: Forming and Performing Femininity. London: Palgrave Macmillan, 2015. 140-163. 
JHRock. "Review of Cibele." Steam 2016. http://steamcommunity.com/id/jhrock/recommended/408120/. Accessed 23 Oct. 2017.

'Kawaii.' Oxford English Dictionary. $3^{\text {rd }}$ ed., 2011.

kbforme. "I have a Question.” Steam 2015. https://steamcommunity.com/app/408120/discussions/0/485624149158764663/. Accessed 23 Oct. 2017.

Kimmy. Developed by Nina Freeman/Star Maid Games, 2016.

Kinggimped. "Review of Cibele." Steam 2015. updated 8 June 2016, http://steamcommunity. $\mathrm{com} / \mathrm{id} /$ facialist/recommended/408120/. Accessed 23 Oct. 2017.

Kirkpatrick, Graeme. The Formation of UK Gaming Culture: UK Gaming Magazines, 1981-1985. London: Palgrave Macmillan, 2015.

Kocurek, Carly. Coin-Operated Americans: Rebooting Boyhood at the Videogame Arcade. Minneapolis: University of Minnesota Press, 2015.

Kraus, Chris. I Love Dick. Los Angeles: Semiotext(e), 1997.

Ladylike. Developed by Nina Freeman/Star Maid Games, 2014.

Lexothesalsashark. "Review of Cibele." Steam 2015. http://steamcommunity.com/id/lexithesalsashark/recommended/408120/. Accessed 23 Oct. 2017.

Lost Memories Dot Net. Developed by Nina Freeman/Star Maid Games, 2017.

McBean, Sam. Feminism's Queer Temporalities. London: Routledge, 2015.

McRobbie, Angela. "Post-Feminism and Popular Culture." Feminist Media Studies 4.3 (2004): 255-264.

Metz, Christian. The Imaginary Signifier: Psychoanalysis and the Cinema. Indiana University Press, 1982.

Milner, Ryan M. and Whitney Phillips. The Ambivalent Internet: Mischief, Oddity and Antagonism Online. Cambridge: Polity, 2017.

Ngai, Sianne. Our Aesthetic Categories: Zany, Cute, Interesting. Cambridge, MA: Harvard University Press, 2015.

Poremba, Cindy. "Play with Me: Exploring the Autobiographical through Digital Games." Situated Play: Proceedings of the DiGRA 2007 Conference, 2007. 703-707.

Renegar, Valerie R. and Stacey K. Sowards. "Liberal Irony, Rhetoric and Feminist Thought: A Unifying Third Wave Feminist Theory." Philosophy and Rhetoric 36.4 (2003): 330-352.

Riesler, Martin and Andrea Zapp. New Screen Media: Cinema/Art/Narrative, Volume One. BFI Publishing, 2002.

Rosenberg, Alyssa. "The Culture Wars are Back and This Time Everyone Can Win." Washington Post 2014. https://www.washingtonpost.com/news/act-four/wp/2014/10/08/theculture-wars-are-back-and-this-time-everyone-can-win/? utm_term=.8411d626813d. Accessed 23 Oct. 2017.

Schwarz, Ori. "On Friendship, Boobs and the Logic of the Catalogue: Online Self-Portraits as Means for the Exchange of Capital." Convergence 16.1 (2010): 163-183.

Senft, Theresa. "Hating Habermas: On Exhibitionism, Shame, and Life on the Actually Existing Internet.” Either/And 2014. http://eitherand.org/exhibitionism/hating-habermasexhibitionism-shame-life-actually-/. Accessed 23 Oct. 2017.

Shugart, Helene. "Postmodern Irony as Subversive Rhetorical Strategy." Western Journal of Communication 63.4 (1999): 433-455.

Shugart, Helene, Catherine Egley Waggoner and D. Lynn O'Brien Hallstein. "Mediating Third-Wave Feminism: Appropriation as Postmodern Media Practice." Critical Studies in Media and Communication 18.2 (2001): 194-210.

Stanton, Domna C. “Autogynography: Is the Subject Different?” Eds. Sidonie Smith and Julia Watson. Women, Autobiography, Theory: A Reader. London: University of Wisconsin Press, 1998. 131-144. 
Sykes, Rachel. "Who Gets to Speak and Why?' Oversharing in Contemporary North American Women's Writing." Signs: Journal of Women in Culture and Society 43.1 (2017): 151-174.

Table Talk. Developed by Nina Freeman, 2015.

Tiidenberg, Katrin. "'Nude Selfies Til I Die': Making of "Sexy” in Selfies." Eds. Paul G. Nixon and Isabel K. Düsterhöft. Sex in the Digital Age. London: Routledge, 2017. 78-88.

Ullman, Ellen. "Come in, CQ: The Body on the Wire." Eds. Lynn Cherny and Elizabeth Reba Weise. Wired Women: Gender and New Realities in Cyberspace. Washington: Seal Press, 1996. $3-23$.

Villanueva, Kaira Zenine. "Nina Freeman on Developing Her New Game, how do you Do it?" The Mary Sue 2015. https://www.themarysue.com/interview-nina-freeman/. Accessed 23 Oct. 2017.

Vincent, J. Keith. "Making It Real: Fiction, Desire and the Queerness of the Beautiful Fighting Girl." Ed. Saito Tamaki. Beautiful Fighting Girl, Minneapolis: Minnesota: University of Minnesota Press, 2011. Ix-xxv.

Waldron, Emma Leigh. “'This FEELS SO REAL!' Sense and Sexuality in ASMR Videos." First Monday 22.1-2 (2017). http://firstmonday.org/ojs/index.php/fm/article/ view/7282/5804. Accessed 23 Oct. 2017.

Warhol, Robyn. Having a Good Cry: Effeminate Feelings and Pop Culture Forms. Columbus: Ohio State UP, 2003.

Werning, Stefan. "The Persona in Autobiographical Game-Making as a Playful Performance of the Self." Persona Studies 3.1 (2017): 28-42.

\section{ABOUT THE AUTHOR}

Rob Gallagher is a postdoctoral researcher with King's College London's EgoMedia project, which considers the role of digital technologies in fostering new forms of life narrative, modes of self-presentation and conceptions of identity. His research has appeared in journals such as Film Theory, Game Studies, Convergence and Games and Culture. He is the author of Videogames, Identity and Digital Subjectivity (Routledge, 2017). Email: robert.gallagher@kcl.ac.uk.

\section{NOTES}

1 Throughout the article I'll be referring to Cibele's protagonist as Nina and the game's creator as Freeman.

2 Sykes 2017, 151-174; Senft 2014.

3 Werning 2017, 29.

4 Poremba 2007, 707.

5 Anna Anthropy's Dys4ia, for example, takes the form of a series of microgames that draw inspiration from 1970s and 1980s Intellivision and Atari titles to dramatize Anthropy's experiences as a trans woman navigating a transphobic world.

6 Sykes 2017, 160.

7 Idem. 151-3, 169.

8 For accounts of how digital gaming came to be coded as masculine in the first place, see Kocurek, 2015, and Kirkpatrick, 2015. 
9 Steam has become the main platform for the sale, distribution and discussion of PC and Mac games.

10 Kbforme 2015.

11 Kinggimped 2016.

12 Anable 2018, xv.

13 Idem xvii.

14 Idem xvii, xii.

15 Villanueva 2015.

16 Riesler and Zapp 2002, 167.

17 Milner and Phillips, 2017.

18 The OED translates the term as 'Cute, esp. in a manner considered characteristic of Japanese popular culture; charming, darling; ostentatiously adorable'.

19 Hudson 2015.

20 Idem.

21 Dobson 2015, 68.

22 Milner and Phillips define a catfish as 'an individual [who] poses as a fictional person, or steals the identity of a real person, in order to "hook" a given target' (75).

23 Sykes 2017, 151.

24 Chun 2016, 158.

25 Dobson 2015, 68-9.

26 Idem 69.

27 Ullman's essay, 'Come in, CQ: The Body on the Wire', is published in Lynn Cherny and Elizabeth Reba Weise's collection Wired Women: Gender and New Realities in Cyberspace.

28 Warhol 2003, 71.

29 Chun 2016, 106.

30 Senft 2014.

31 Cibele was also the name of Freeman's Final Fantasy XI character, and is presumably a reference to the ancient fertility deity Cybele, a 'healer [and] protector' (Coulter and Turner 2012, 137).

32 Brehm 2013, 8, 7.

33 Eklund 2011, 332.

34 ibid 332, 329, 335.

35 Schwarz 2010. Schwarz defines corporeal capital as a form of 'social currency' manifested in images 'understood as indexical of the physical body'. It encompasses both 'congenital bodily characteristics' and 'manipulations executed on the body: diet, fitness, piercing, hairdo, clothes' as well as 'posing, shooting angles, camera effects, Photoshop manipulations' and 'mastery of visual codes, mostly borrowed from the advertising and fashion industries' (171).

36 Tiidenberg 2017, 78.

37 Milner and Phillips 2017, 10. Emphasis in original.

38 Ngai 2015, 72, 60, 66, 85 .

39 Dobson 2015, 55, 58.

40 Idem 60. Emphases in original.

41 Idem 67, 62-64. Emphases in original.

42 This relationship is further explored in Lost Memories Dot Net, in which players decorate the 13-year-old Nina's blog with selfies, images of anime heroines, and shots of female celebrities.

43 Denoting devotees of anime, manga and videogames, the term carries connotations of social isolation and sexual deviance in Japan (Azuma 2009, 4-5), though Western devotees of Japanese pop culture have repurposed it as a badge of pride. 
44 Which itself hovers between the innocuous and the obscene; as Gustainis (1999) notes, 'the "V for Victory" symbol made so famous by Prime Minister Winston Churchill' reversed a 'a vulgar British/Irish gesture' (408).

45 Vincent 2011, x.

46 Gwynne 2013, 329.

47 Iseri 2015, 141, 140.

48 Idem 160.

49 Ngai 2015, 78.

50 Vincent 2011, xiii.

51 'Sexually explicit or pornographic manga and anime' (OED).

52 See Emma Maguire's contribution to this issue.

53 Gallagher 2014, 44-5.

54 Illouz 2012, 229-230.

55 Idem.

56 Idem 231, 230.

57 "In real life." The $O E D$ traces the acronym to late 1980 s Usenet message boards.

58 Vincent 2011, x, xv, xix.

59 Christian Metz (1982) famously asserts that the viewer's 'primary cinematic identification' is with the apparatus rather than the performers on screen (55-6).

60 Waldron 2017.

61 Vincent 2011, xvi.

62 Anable 2018, xi.

63 Ed0022 2017.

64 Bee 2016.

65 Lexothesalsashark 2015.

66 Kinggimped 2016.

67 A Dolphin 2016.

68 Cross 2015.

69 Stanton 1998, 132.

70 JHRock 2016.

71 Kinggimped 2016.

72 Rosenberg 2014.

73 Gilmore 2017, 2, 98.

74 Idem 91, 95.

75 Idem 94.

76 For an elaboration of these reasons, see Sam McBean's Feminism's Queer Temporalities (2015).

77 Shugart, Waggoner, and O'Brien Hallstein 2001,195-7; Renegar and Sowards 2003, 331.

78 Dicker and Piepmeier 2003, 16.

79 Shugart 1999, 434.

80 McRobbie 2004, 255-264.

81 Schwarz 2010, 164.

82 Kraus 1997, 137.

83 Sykes 2017, 152, 162. 